\title{
Bradykinin stimulates IL-6 production and cell invasion in colorectal cancer cells
}

\author{
GUOJUN WANG, YANWEI YE, XIEFU ZHANG and JUNMIN SONG \\ Department of Gastrointestinal Surgery, The First Affiliated Hospital \\ of Zhengzhou University, Zhengzhou, Henan 450052, P.R. China
}

Received March 20, 2014; Accepted June 24, 2014

DOI: $10.3892 /$ or.2014.3366

\begin{abstract}
Bradykinin (BK) has been reported to be involved in the progression of many types of cancer. In the present study, we investigated a possible role of BK in colorectal cancer cell invasion and migration. Invasion and migration assays showed that BK treatment promoted the invasion and migration of colorectal cancer cells. Further experiments showed that BK treatment stimulated ERK1/2 activation and IL-6 production. Two bradykinin receptors, bradykinin $\mathrm{B} 1$ receptor $(\mathrm{B} 1 \mathrm{R})$ and bradykinin $\mathrm{B} 2$ receptor $(\mathrm{B} 2 \mathrm{R})$, were significantly expressed in all the tested colorectal cancer cells. Repression of B2R, but not B1R, attenuated the BK-mediated invasion and migration, and inhibited ERK1/2 activation and IL-6 production. Moreover, blocking of the ERK pathway decreased the BK-mediated IL- 6 production. In addition, IL-6 repression suppressed the effects of BK on colorectal cancer cell invasion and migration. Taken together, the present study demonstrated that BK increases IL- 6 production via $\mathrm{B} 2 \mathrm{R}$ and the ERK pathway, thereby contributing to the invasion and migration of colorectal cancer cells. Thus, our findings may provide benefits for the treatment of colorectal cancer.
\end{abstract}

\section{Introduction}

As a member of the kinin group, bradykinin (BK) is an active peptide that is generated by the kallikrein-kinin system (KKS) (1). It is reported that BK is involved in the regulation of various cellular processes in cancer cells including tumorigenesis, angiogenesis, cell cycle and proliferation (2). BK exerts its biological functions mainly via the binding of bradykinin receptors, which are pharmacologically characterized as bradykinin $\mathrm{B} 1$ receptor $(\mathrm{B} 1 \mathrm{R})$ and bradykinin B2 receptor (B2R) (3). B1R and B2R both belong to the G-protein coupled receptors (4). B1R induces COX-2

Correspondence to: Dr Guojun Wang, Department of Gastrointestinal Surgery, The First Affiliated Hospital of Zhengzhou University, 1 Jianshe Road, Zhengzhou, Henan 450052, P.R. China E-mail: gjwang15@163.com

Key words: bradykinin, bradykinin B2 receptor, IL-6, invasion, ERK pathway, colorectal cancer production and cell migration in glioma cells (5), whereas B2R promotes VEGF expression and increases angiogenesis in prostate cancer cells (6). Therefore, activation of these two receptors by bradykinin may be essential for the development and progression of cancer.

Colorectal cancer is one of the most common malignancies worldwide. Over 600,000 deaths from colorectal cancer are estimated to occur annually worldwide, thus ranking it as the fourth cause of death among cancer patients (7). Although therapeutic strategies have been well developed, colorectal cancer often progresses, along with cell invasion and metastasis (8). Invasion and metastasis are still the major cause of cancer-related mortality (9). Studies have found that BK can induce MMP-3 expression in human colonic myofibroblasts, which may then contribute to the pathophysiology underlying colitis-associated cancer (10). However, the role of BK in colorectal cancer remains elusive. In this study, we examined the effect of $\mathrm{BK}$ treatment on the invasion and migration of colorectal cancer cells. We further characterized the function of B2R in BK-mediated invasion and migration, and determined the possible underlying mechanisms.

\section{Materials and methods}

Reagents. The antibodies against B1R (rabbit monoclonal antibody), B2R (mouse monoclonal antibody), $\beta$-actin (mouse monoclonal antibody) and ERK1/2 (rabbit polyclonal antibody) were obtained from Santa Cruz Biotechnology, Inc. (Santa Cruz, CA, USA). The antibody against phospho-ERK1/2 (rabbit polyclonal antibody) was obtained from Cell Signaling Technology, Inc. (Beverly, MA, USA). BK and PD98059 were purchased from Sigma (St. Louis, MO, USA). IL-6 ELISA kit was purchased from Boster (Wuhan, China).

Cell culture. Human colorectal cancer cell lines, T84, Caco-2, HT-29, HCT116 and SW480, were purchased from the American Type Culture Collection (Manassas, VA, USA). Cells were maintained in Dulbecco's modified Eagle's medium (DMEM; Gibco-BRL, Rockville, MD, USA) with $10 \%$ fetal bovine serum (FBS; Gibco-BRL) at $37^{\circ} \mathrm{C}$ in a humidified $\mathrm{CO}_{2}$ incubator.

Invasion assay. A 24-well Transwell plate, containing PET membranes with $8-\mu \mathrm{m}$ pores, was purchased from 
Costar (San Diego, CA, USA). The upper chambers of the plate were coated with thin layers of Matrigel (BD Biosciences, Franklin Lakes, NJ, USA). Cells $\left(1.0 \times 10^{5}\right.$ cells in $0.2 \mathrm{ml}$ DMEM/well) were pretreated with different dosages of bradykinin, and then were added to the upper chambers. The chemoattractant $(20 \%$ FBS) was placed into the lower chambers. After incubation in a $\mathrm{CO}_{2}$ incubator for $16 \mathrm{~h}$, the cells that invaded through the membrane were fixed and stained with eosin. The invaded cells were observed under a microscope (magnification, $\mathrm{x} 100$ ), and the number of the invaded cells was counted from five random fields. All experiments were conducted in triplicate, and the data are presented as a percentage of the invaded cells in the control.

Migration assay. The procedure for the migration assay was similar to the invasion assay described above, except that the upper chambers were coated without Matrigel. Briefly, cells were adjusted to the concentration of $5.0 \times 10^{5}$ cells $/ \mathrm{ml}$. Two hundred microliters of the cell suspensions was placed in the upper chambers, while $20 \%$ FBS was placed into the lower chambers. Sixteen hours later, the migrated cells were stained with eosin. The number of migrated cells was counted from five random fields, and the data are presented as a percentage of the migrated cells in the control.

Western blot analysis. Cells were lysed in $200 \mu 1$ lysis buffer, which contained $50 \mathrm{mM}$ Tris- $\mathrm{HCl}(\mathrm{pH} 7.5), 1 \% \mathrm{NP}-40$, $150 \mathrm{mM} \mathrm{NaCl}, 1 \mathrm{mg} / \mathrm{ml}$ aprotinin, $1 \mathrm{mg} / \mathrm{ml}$ leupeptin, $1 \mathrm{mM}$ $\mathrm{Na}_{3} \mathrm{VO}_{4}$ and $1 \mathrm{mM} \mathrm{NaF}$. The protein concentrations were determined by BCA assay. Equal amounts of cell lysate $(50 \mu \mathrm{g})$ were resolved by $10 \%$ SDS-PAGE and transferred to a PVDF membrane (Pall Corp., Alcobendas, Spain). After blocking with $5 \%$ non-fat milk (for detection of B1R, B2R, $\beta$-actin and ERK1/2) or 5\% BSA (for detection of p-ERK1/2) for $1 \mathrm{~h}$ at room temperature, the membranes were incubated with primary antibodies overnight at $4^{\circ} \mathrm{C}$. Then the membranes were washed with TBST for three times and further incubated with the secondary antibodies for $1 \mathrm{~h}$ at room temperature. The bands were detected with an enhanced chemiluminescence kit (Applygen Technologies Inc., Beijing, China), according to the manufacturer's instructions. The density of the bands was quantified with Quantity One software.

siRNA transfection. siRNAs were designed and chemically synthesized by Genepharma (Shanghai, China). The sequences of the siRNAs are listed as follows: control siRNA, 5'-UGG UUUACAUGUUUUCUGA-3'; B1R siRNA, 5'-GCUCCC UGAAUCCAGUAAU-3'; B2R siRNA, 5'-GGCAGAGGA AGAUAUUUCU-3'; IL-6 siRNA, 5'-CCCGGACCAUAU UUAUUAU-3'. Cells were transfected with siRNAs using Lipofectamine 2000 ${ }^{\mathrm{TM}}$ (Invitrogen, Carlsbad, CA, USA) when the cell confluency reached $30-40 \%$. The knockdown efficiency was determined by western blotting or real-time PCR.

ELISA assay. The level of IL-6 in the culture supernatant was observed by ELISA assay, according to the manufacturer's instructions. Briefly, cells were treated with or without BK for $16 \mathrm{~h}$, and then $50 \mu \mathrm{l}$ of the cell supernatant was added into the ELISA plate wells to detect the level of IL-6. The absorbance
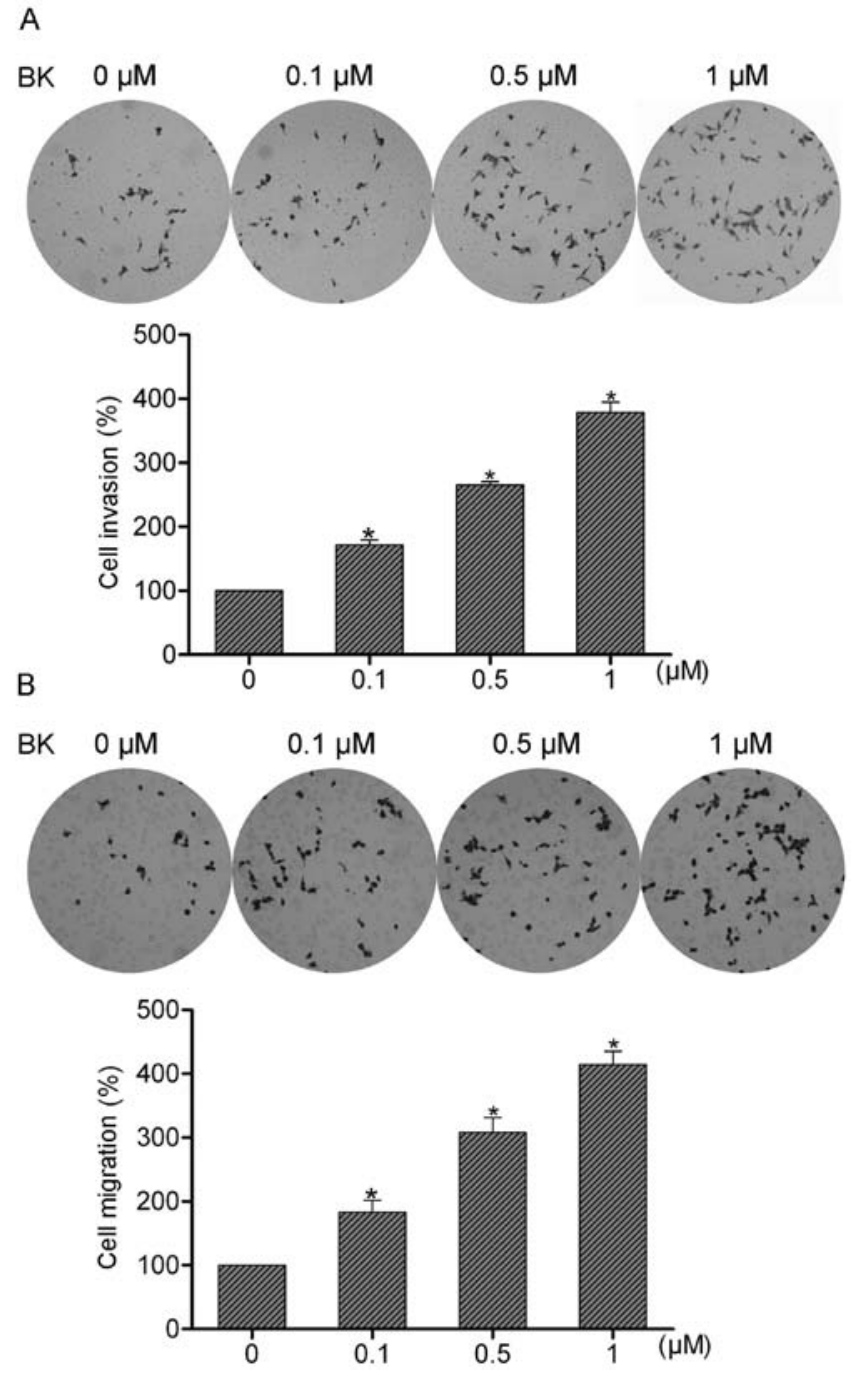

Figure 1. SW480 cells were pretreated with different concentrations of BK (0.1-1 $\mu \mathrm{M})$, and then subjected to invasion and migration assays. (A) Effect of BK treatment on the invasion of SW480 cells. (B) Effect of BK treatment on the migration of SW480 cells. ${ }^{*} \mathrm{P}<0.05$.

was measured at $450 \mathrm{~nm}$ in a microplate reader. The concentration of IL- 6 was examined by comparing the absorbance values against the standard curve. The level of IL-6 in each sample was quantified to the total protein.

Real-time PCR. Total-RNA was isolated from the SW480 cells by using TRIzol reagent (Invitrogen, Carlsbad, CA, USA). The concentrations of RNA were measured with NanoDrop ND-1000 (Thermo Fisher Scientific, Wilmington, DE, USA). The reverse transcription PCR reaction was carried out with $2 \mu \mathrm{g}$ of RNA and M-MLV reverse transcriptase (Tiangen, Beijing, China) to obtain cDNA. Then the real-time PCR reaction was performed with cDNA and primers. Oligonucleotide primers are listed as follows: IL-6 sense, 5'-TGCGTCCGTAGTTTCCTTCT-3' and antisense, 5'-GCCTCAGACATCTCCAGTCC-3'; $\beta$-actin sense, 5'-AGAAGGATTCCTATGTGGGCG-3' and antisense, 5'-CATGTCGTCCCAGTTGGTGAC-3'. The reaction was performed for $5 \mathrm{~min}$ at $95^{\circ} \mathrm{C}$, followed by 40 cycles of $95^{\circ} \mathrm{C}$ for $15 \mathrm{sec}$, and $60^{\circ} \mathrm{C}$ for $1 \mathrm{~min}$. 
A

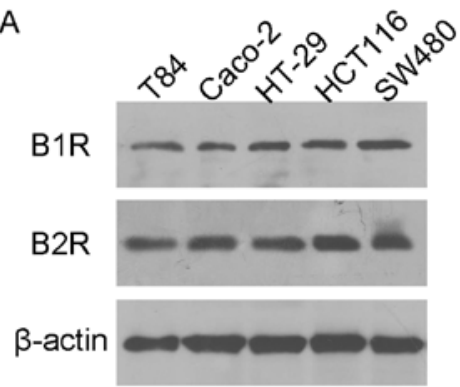

B
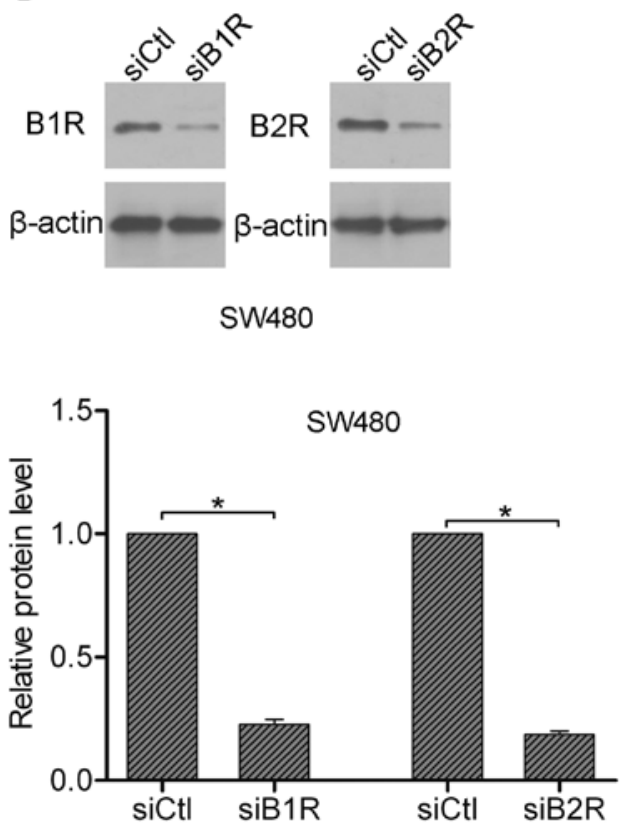

Figure 2. Protein levels of $\mathrm{B} 1 \mathrm{R}$ and $\mathrm{B} 2 \mathrm{R}$ in colorectal cancer cells. (A) Western blot analysis of $\mathrm{B} 1 \mathrm{R}$ and $\mathrm{B} 2 \mathrm{R}$ protein expression in $\mathrm{T} 84$, Caco-2, HT-29, HCT116 and SW480 cells. (B) Suppression of B1R and B2R expression by siRNA. Cells were transfected with B1R siRNA (siB1R), B2R siRNA (siB2R) or control siRNA (siCtl), respectively. The protein expression of B1R and B2R in SW480 cells was determined by western blotting. ${ }^{*} \mathrm{P}<0.05$.

Statistical analysis. All experiments were repeated three to four times, and the data are presented as the mean \pm SEM. The data were analyzed by the Student's t-test between two groups or one-way ANOVA between multiple groups. $\mathrm{P}<0.05$ was considered to indicate a statistically significant difference.

\section{Results}

$B K$ enhances the invasion and migration of colorectal cancer cells. To examine the role of BK in colorectal cancer cell invasion and migration, SW480 cells were treated with $0.1,0.5$ or $1 \mu \mathrm{M} \mathrm{BK}$, respectively. Then the treated or untreated cells were subjected to invasion and migration assays. The invaded or migrated cells were observed and quantified $16 \mathrm{~h}$ later. The data showed that BK treatment resulted in a concentrationdependent increase in the invasive and migratory abilities of the SW480 cells (Fig. 1A and B), indicating that BK may be an important modulator of colorectal cancer cell invasion and migration.
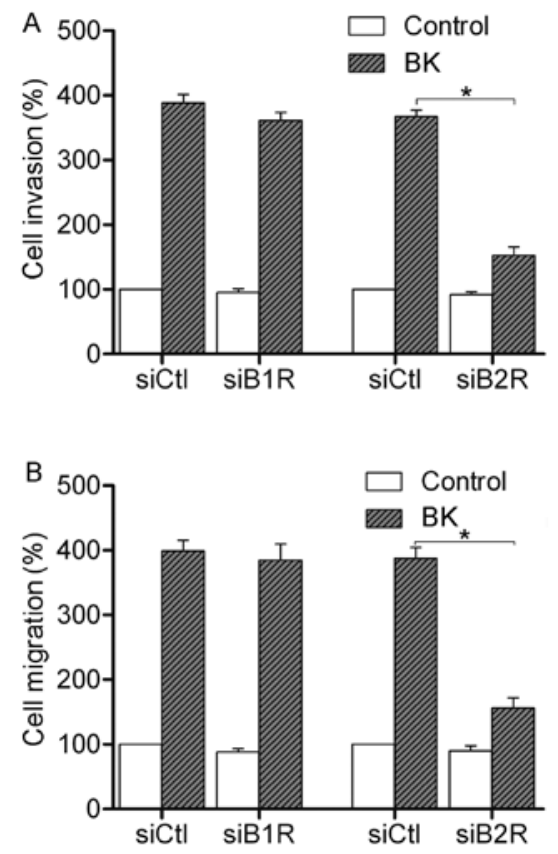

Figure 3. Effects of B1R and B2R on the invasion and migration of SW480 cells. After suppression of B1R or B2R by siRNAs, cells were treated with or without $1 \mu \mathrm{M}$ BK. Subsequently, (A) invasion and (B) migration assays were carried out using Transwell plates. ${ }^{*} \mathrm{P}<0.05$.

Expression of bradykinin receptors in colorectal cancer cells and suppression of bradykinin receptors by siRNA. It is known that $\mathrm{BK}$ acts via bradykinin receptors, which are further characterized as B1R and B2R (3). Here, we detected the expression of B1R and B2R in colorectal cancer cells. As shown in Fig. 2A, all tested cell lines expressed significant amounts of B1R and B2R protein. Next, a B1R siRNA was generated to silence the expression of B1R, while a B2R siRNA was generated to silence the expression of B2R. As observed by western blot analysis, both B1R siRNA and B2R siRNA achieved prominent knockdown efficiency in the SW480 cells (Fig. 2B).

$B 2 R$ suppression leads to inhibition of BK-mediated invasion and migration in colorectal cancer cells. We further tested the effect of RNAi-mediated B1R and B2R suppression on the invasion and migration of colorectal cancer cells. Invasion and migration assays were performed after BK treatment. As shown in Fig. 3, $1 \mu \mathrm{M}$ BK treatment promoted the invasion and migration in the control siRNA cells. Suppression of B1R had little effect on the BK-mediated invasion and migration. However, suppression of $\mathrm{B} 2 \mathrm{R}$ resulted in a reduction in BK-mediated invasion and migration in SW480 cells. Together, these data suggest that it is B2R that participates in the BK-mediated invasion and migration of colorectal cancer cells.

$B 2 R$ is required for $B K$-mediated ERK1/2 activation. Previous studies have shown that BK can induce multiple intracellular signaling pathways of cancer cells including the ERK pathway (11). However, the relationship between BK and the ERK pathway in colorectal cancer cells is, to our knowledge, not yet clear. We, therefore, stimulated SW480 cells with 

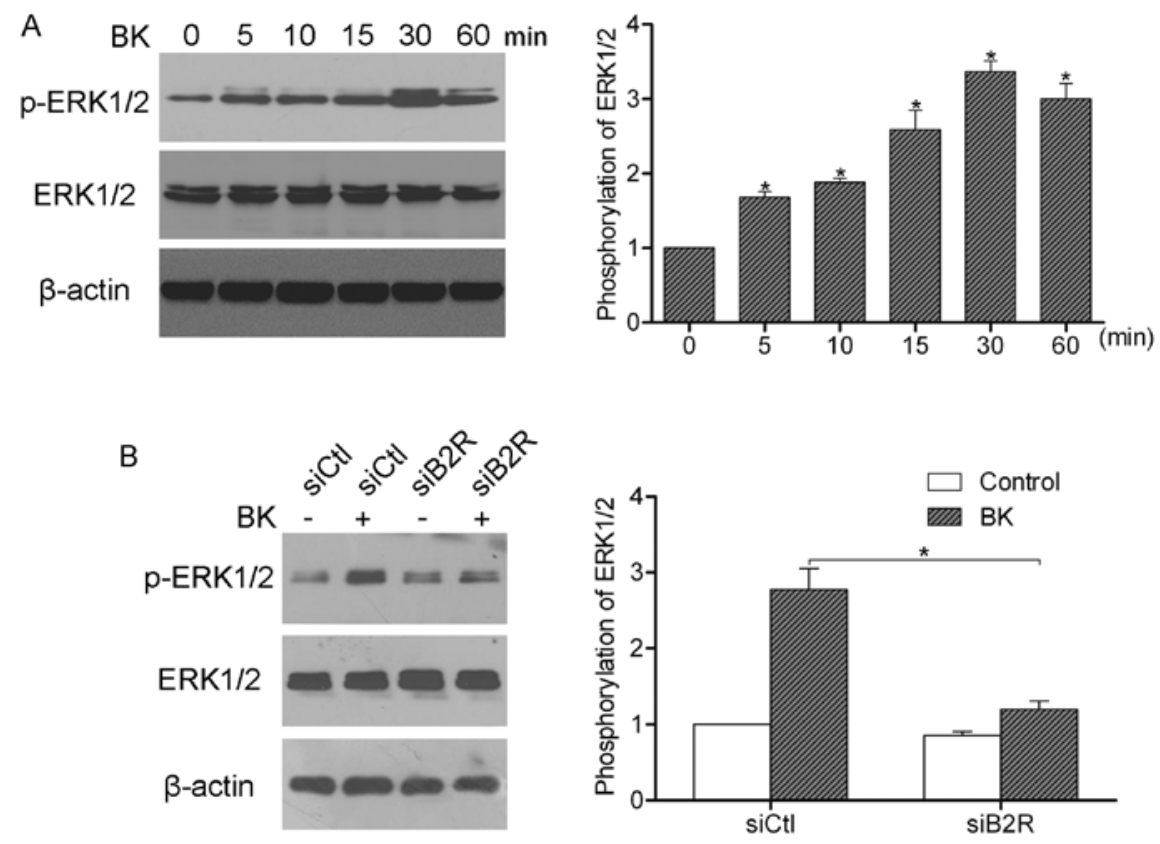

Figure 4. BK induces the activation of ERK1/2 via B2R. (A) SW480 cells were treated with $1 \mu \mathrm{M}$ BK, and the phosphorylation of ERK1/2 was assessed within $1 \mathrm{~h}$ by western blot analysis. (B) After transfection with B2R siRNA (siB2R) or control siRNA (siCtl), SW480 cells were incubated with $1 \mu \mathrm{M}$ BK or without for 30 min. Western blotting was performed to examine the phosphorylation of ERK1/2. $\mathrm{P}<0.05$.
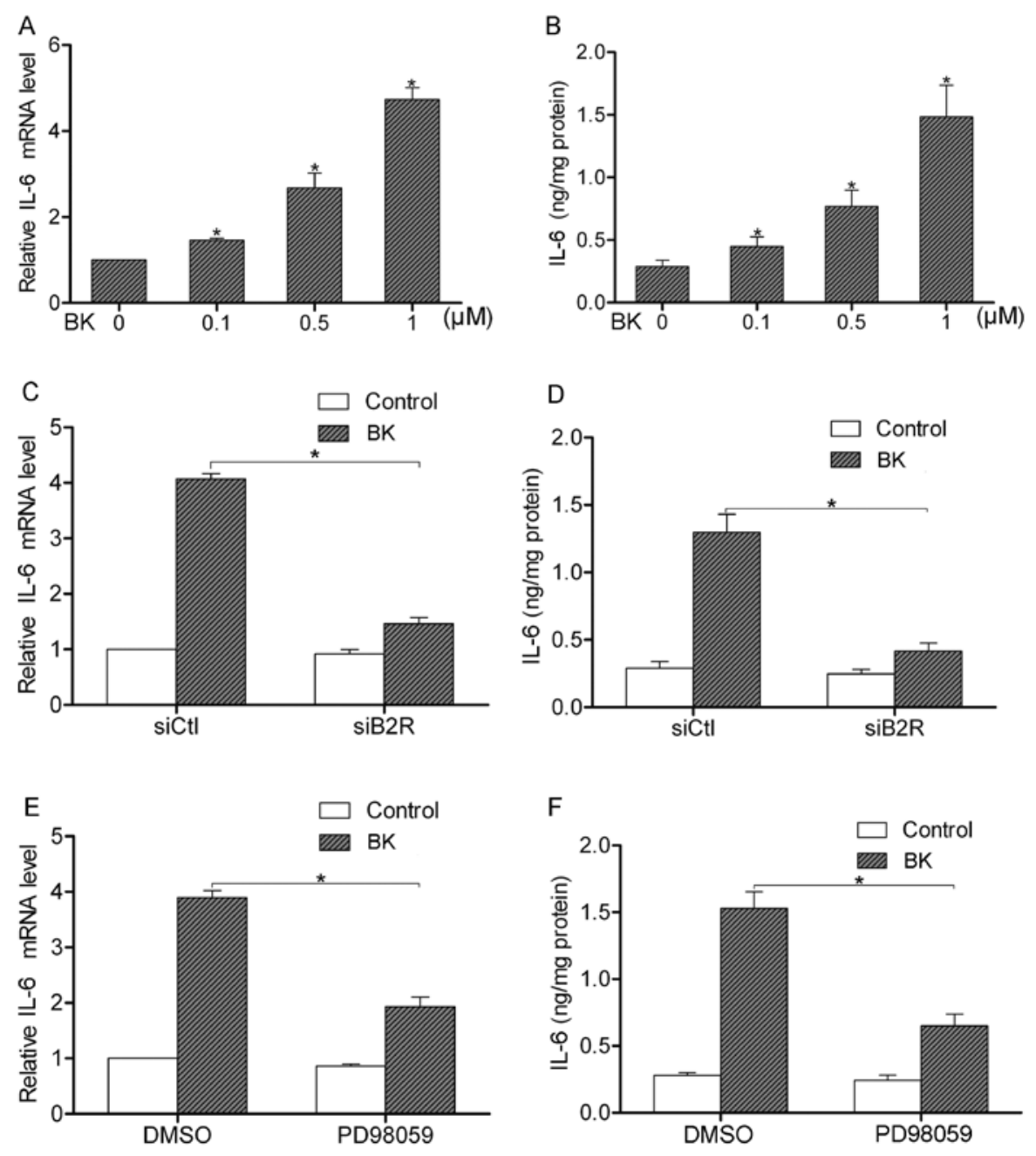

Figure 5. The B2R-ERK pathway contributes to BK-induced IL-6 production. (A and B) Cells were incubated with different concentrations of BK for $16 \mathrm{~h}$ and the mRNA level of IL-6 was detected by real-time PCR (A) and the secretion of IL-6 was examined by ELISA assay (B). (C and D) Effects of B2R on the expression and secretion of IL-6. (E and F) Effects of ERK1/2 on the expression and secretion of IL-6. ${ }^{*} \mathrm{P}<0.05$. 

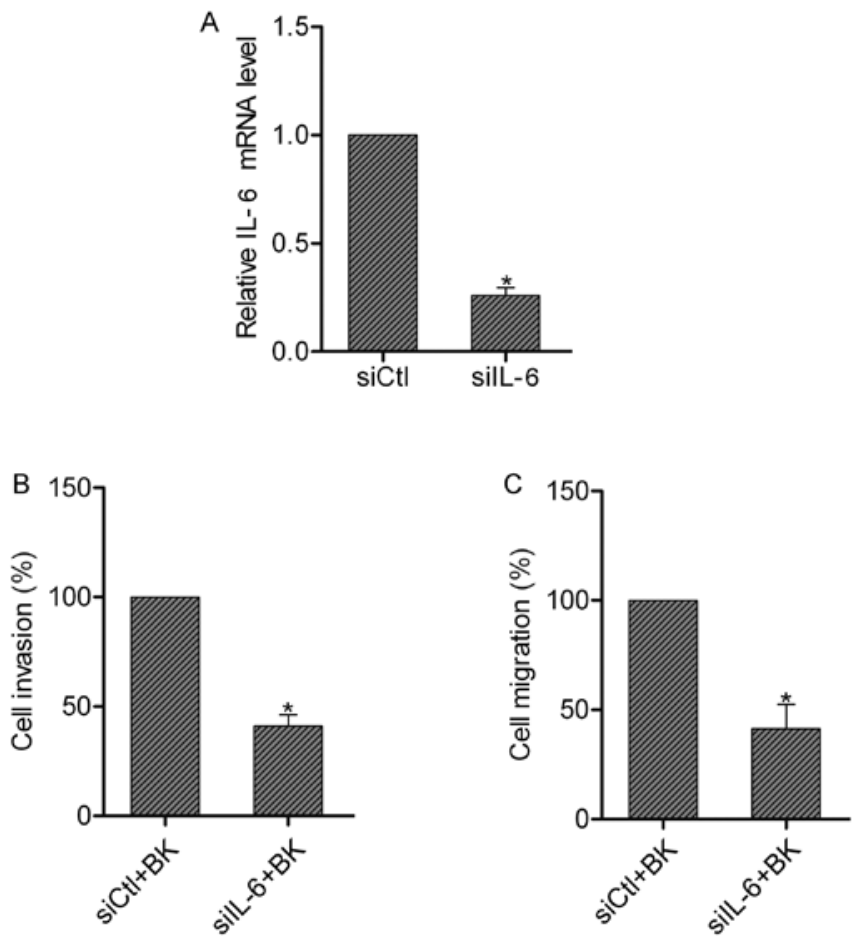

Figure 6. IL-6 is involved in the BK-enhanced invasion and migration in SW480 cells. (A) IL-6 mRNA expression was determined by real-time PCR $48 \mathrm{~h}$ after transfection with IL-6 siRNA (siIL-6) or control siRNA (siCtl). (B and C) After transfection with IL-6 siRNA or control siRNA, cells were incubated with $1 \mu \mathrm{M}$ BK for $16 \mathrm{~h}$. Subsequently, (B) invasion and (C) migration were determined by Transwell assay. ${ }^{*} \mathrm{P}<0.05$.

$1 \mu \mathrm{M}$ BK for $60 \mathrm{~min}$, and then examined the phosphorylation of ERK1/2 by western blot analysis. The results showed that BK treatment induced the activation of ERK1/2, and the peak activation was observed after $30 \mathrm{~min}$ (Fig. 4A). Furthermore, we silenced B2R expression by siRNA and stimulated cells with $1 \mu \mathrm{M}$ BK for $30 \mathrm{~min}$. Western blot analysis showed that suppression of B2R inhibited the BK-mediated activation of ERK1/2, suggesting that BK induces ERK1/2 activation via B2R (Fig. 4B).

BK stimulates IL-6 production through the B2R-ERK pathway. $\mathrm{BK}$ treatment is able to induce the secretion of various cytokines such as IL-1 $\beta$, IL-8 and IL-12 (12). Using real-time PCR and ELISA assay, we found that BK treatment $(0.1-1 \mu \mathrm{M})$ increased the expression and secretion of IL- 6 in the SW480 cells (Fig. 5A and B). We, then, silenced the expression of B2R by siRNA to analyze the effect of B2R on the BK-induced IL- 6 production. We found that BK upregulated the expression and secretion of IL-6 in the control cells. However, after suppression of B2R by siRNA, the BK-mediated IL- 6 production was greatly decreased (Fig. 5C and D). Furthermore, we pretreated SW480 cells with PD98059, a specific inhibitor of ERK1/2, to observe the function of the ERK pathway in the regulation of IL-6 production. The results showed that inactivation of ERK1/2 attenuated the BK-induced IL-6 production (Fig. 5E and F). Taken together, these data indicate that the B2R-ERK pathway is necessary for BK-induced IL-6 production.

IL- 6 contributes to the BK-mediated invasion and migration of colorectal cancer cells. To reveal the role of IL-6 in invasion and migration, we silenced the expression of IL-6 in SW480 cells by siRNA (Fig. 6A). Then we subjected these cells to invasion and migration assays following BK treatment. We found that IL- 6 suppression resulted in the inhibition of invasion and migration in the SW480 cells pretreated with BK, suggesting the involvement of IL-6 in the BK-mediated invasion and migration of colorectal cancer cells (Fig. 6B and C).

\section{Discussion}

As the most prominent member of the kinin group, bradykinin $(\mathrm{BK})$ is an important player in the regulation of inflammation and cancer $(13,14)$. Accumulating research shows that BK treatment can induce the activation of multiple intracellular pathways such as MAPK and PI3K/AKT signaling pathways in cancer cells $(5,15)$, and thus contributes to the proliferation, angiogenesis and migration of cancer cells (16-18). Our present study demonstrated for the first time that BK treatment activated B2R and ERK1/2, which then led to an increase in IL-6 production, which finally promoted cell invasion and migration of colorectal cancer cells. These data strongly support the conclusion that BK is a potent stimulator of colorectal cancer cell invasion and migration.

BK exerts its effects via bradykinin receptors, which are categorized as B1R and B2R. B1R and B2R are both implicated in the progression of cancer. Studies have found that $\mathrm{B} 1 \mathrm{R}$ and $\mathrm{B} 2 \mathrm{R}$ are highly expressed in the cytoplasm of lung cancer, and B2R is overexpressed in head and neck squamous cell carcinomas $(19,20)$. Using western blot analysis, we observed significant expression levels of B1R and B2R in all of the examined colorectal cancer cells, indicating a role of bradykinin receptors in colorectal cancer. It was also found that $\mathrm{BK}$ has a higher affinity to $\mathrm{B} 2 \mathrm{R}$ as compared to B1R (12). Activation of $\mathrm{B} 2 \mathrm{R}$ by $\mathrm{BK}$ promotes the growth and migration of prostate cancer cells $(21,22)$. In the present study, we found that B2R suppression attenuated the BK-mediated invasion and migration of SW480 cells, whereas B1R suppression did not have an impact on the effect of BK on colorectal cancer cells. Thus, it appears that B2R, but not B1R, participates in regulating the $\mathrm{BK}$-enhanced invasion and migration of colorectal cancer cells.

Numerous signaling pathways have been reported to be activated by BK, notably the MAPK, PKC and NF- $\kappa$ B pathways $(11,23,24)$. Our results showed that BK treatment induced the activation of ERK1/2 through B2R. These findings suggest that the ERK pathway may contribute to the BK-mediated invasion and migration of colorectal cancer cells, as it is well known that the ERK pathway plays a pivotal role in colorectal cancer dissemination (25).

Of note, BK treatment is able to stimulate the generation of various cytokines such as IL-1 and tumor necrosis factor (TNF) (26). Studies have found that BK induces IL-6 secretion in lung fibroblasts (27). However, little is known concerning the effect of BK on IL- 6 production in cancer cells. Here, we found that BK induced the expression and secretion of IL-6 via the B2R-ERK pathway. To the best of our knowledge, our findings are the first to show that BK treatment increases IL- 6 production in colorectal cancer cells. IL- 6 expression is frequently upregulated in various types of human cancers (28-30). Clinical data have shown that 
IL-6 expression in tumor tissues correlates with lymph node metastasis of colorectal cancer (31), whereas experimental studies confirm that IL-6 promotes cell proliferation, invasion and metastasis of cancers (32-34). We found that suppression of IL-6 in SW480 cells decreased the BK-mediated invasion and migration, confirming that IL- 6 plays an important role in colorectal cancer.

In conclusion, our study demonstrated that BK treatment enhanced the invasion and migration of colorectal cancer cells. Suppression of B2R attenuated the BK-mediated invasion and migration. The possible mechanism involved BK-stimulated B2R, subsequently leading to the activation of the ERK pathway and upregulation of IL-6 production. Therefore, it is likely that B2R may be a potential therapeutic target for the treatment of colorectal cancer.

\section{Acknowledgements}

This research was supported by grants from the National Natural Science Foundation of China (81201955).

\section{References}

1. Moreau ME, Garbacki N, Molinaro G, Brown NJ, Marceau F and Adam A: The kallikrein-kinin system: current and future pharmacological targets. J Pharmacol Sci 99: 6-38, 2005.

2. Maeda H, Wu J, Okamoto T, Maruo K and Akaike T: Kallikreinkinin in infection and cancer. Immunopharmacology 43: 115-128, 1999.

3. Regoli D: Pharmacology of bradykinin and related kinins. Adv Exp Med Biol 156: 569-584, 1983.

4. Marceau F and Regoli D: Bradykinin receptor ligands: therapeutic perspectives. Nat Rev Drug Discov 3: 845-852, 2004.

5. Lu DY, Leung YM, Huang SM and Wong KL: Bradykinininduced cell migration and COX-2 production mediated by the bradykinin B1 receptor in glioma cells. J Cell Biochem 110 141-150, 2010.

6. Yu HS, Wang SW, Chang AC, et al: Bradykinin promotes vascular endothelial growth factor expression and increases angiogenesis in human prostate cancer cells. Biochem Pharmacol 87: 243-253, 2014.

7. Siegel R, Ma J, Zou Z and Jemal A: Cancer statistics, 2014. CA Cancer J Clin 64: 9-29, 2014

8. Glimelius B and Cavalli-Bjorkman N: Metastatic colorectal cancer: current treatment and future options for improved survival. Medical approach - present status. Scand J Gastroenterol 47 296-314, 2012.

9. Dashwood RH: Early detection and prevention of colorectal cancer (Review). Oncol Rep 6: 277-281, 1999.

10. Yoo J, Rodriguez Perez CE, Nie W, Sinnett-Smith J and Rozengurt E: Protein kinase D1 mediates synergistic MMP-3 expression induced by TNF- $\alpha$ and bradykinin in human colonic myofibroblasts. Biochem Biophys Res Commun 413: 30-35, 2011.

11. Hsieh HL, Wu CY and Yang CM: Bradykinin induces matrix metalloproteinase-9 expression and cell migration through a PKC-delta-dependent ERK/Elk-1 pathway in astrocytes. Glia 56: 619-632, 2008

12. da Costa PL, Sirois P, Tannock IF and Chammas R: The role of kinin receptors in cancer and therapeutic opportunities. Cancer Lett 345: 27-38, 2014.

13. Colman RW: Regulation of angiogenesis by the kallikrein-kinin system. Curr Pharm Des 12: 2599-2607, 2006.

14. Kashuba E, Bailey J, Allsup D and Cawkwell L: The kinin-kallikrein system: physiological roles, pathophysiology and its relationship to cancer biomarkers. Biomarkers 18: 279-296, 2013.
15. Greco S, Elia MG, Muscella A, Romano S, Storelli C and Marsigliante S: Bradykinin stimulates cell proliferation through an extracellular-regulated kinase 1 and 2-dependent mechanism in breast cancer cells in primary culture. J Endocrinol 186: 291-301, 2005.

16. Searovic P, Alonso M, Oses C, Pereira-Flores K, Velarde V and Saez CG: Effect of tamoxifen and retinoic acid on bradykinin induced proliferation in MCF-7 cells. J Cell Biochem 106: 473-481, 2009.

17. Ikeda Y, Hayashi I, Kamoshita E, et al: Host stromal bradykinin B2 receptor signaling facilitates tumor-associated angiogenesis and tumor growth. Cancer Res 64: 5178-5185, 2004.

18. Yang WH, Chang JT, Hsu SF, et al: Bradykinin enhances cell migration in human chondrosarcoma cells through BK receptor signaling pathways. J Cell Biochem 109: 82-92, 2010.

19. Chee J, Naran A, Misso NL, Thompson PJ and Bhoola KD: Expression of tissue and plasma kallikreins and kinin B1 and B2 receptors in lung cancer. Biol Chem 389: 1225-1233, 2008.

20. Zhang W, Bhola N, Kalyankrishna S, et al: Kinin b2 receptor mediates induction of cyclooxygenase- 2 and is overexpressed in head and neck squamous cell carcinomas. Mol Cancer Res 6: 1946-1956, 2008.

21. Yu HS, Lin TH and Tang CH: Bradykinin enhances cell migration in human prostate cancer cells through $\mathrm{B} 2$ receptor/PKC $/ \mathrm{c}-\mathrm{Src}$ dependent signaling pathway. Prostate 73: 89-100, 2013.

22. Srinivasan D, Kosaka AH, Daniels DV, Ford AP and Bhattacharya A: Pharmacological and functional characterization of bradykinin B2 receptor in human prostate. Eur J Pharmacol 504: 155-167, 2004.

23. Sabatini F, Luppi F, Petecchia L, et al: Bradykinin-induced asthmatic fibroblast/myofibroblast activities via bradykinin B2 receptor and different MAPK pathways. Eur J Pharmacol 710: 100-109, 2013

24. Lee CH, Shieh DC, Tzeng CY, et al: Bradykinin-induced IL-6 expression through bradykinin $\mathrm{B} 2$ receptor, phospholipase $\mathrm{C}$, protein kinase Cdelta and NF-kappaB pathway in human synovial fibroblasts. Mol Immunol 45: 3693-3702, 2008.

25. Sosa MS, Avivar-Valderas A, Bragado P, Wen HC and AguirreGhiso JA: ERK $1 / 2$ and $\mathrm{p} 38 \alpha / \beta$ signaling in tumor cell quiescence: opportunities to control dormant residual disease. Clin Cancer Res 17: 5850-5857, 2011.

26. Tiffany CW and Burch RM: Bradykinin stimulates tumor necrosis factor and interleukin-1 release from macrophages. FEBS Lett 247: 189-192, 1989.

27. Hayashi R, Yamashita N, Matsui S, et al: Bradykinin stimulates IL-6 and IL-8 production by human lung fibroblasts through ERK- and p38 MAPK-dependent mechanisms. Eur Respir J 16: 452-458, 2000

28. Knüpfer $\mathrm{H}$ and Preiss R: Serum interleukin-6 levels in colorectal cancer patients - a summary of published results. Int J Colorectal Dis 25: 135-140, 2010.

29. Dethlefsen C, Højfeldt G and Hojman P: The role of intratumoral and systemic IL-6 in breast cancer. Breast Cancer Res Treat 138: 657-664, 2013.

30. De Vita F, Orditura M, Auriemma A, Infusino S, Roscigno A and Catalano G: Serum levels of interleukin- 6 as a prognostic factor in advanced non-small cell lung cancer. Oncol Rep 5: 649-652, 1998.

31. Ashizawa T, Okada R, Suzuki Y, et al: Study of interleukin-6 in the spread of colorectal cancer: the diagnostic significance of IL-6. Acta Med Okayama 60: 325-330, 2006.

32. Li R, Li G, Deng L, et al: IL-6 augments the invasiveness of U87MG human glioblastoma multiforme cells via up-regulation of MMP-2 and fascin-1. Oncol Rep 23: 1553-1559, 2010.

33. Zheng T, Hong X, Wang J, et al: Gankyrin promotes tumor growth and metastasis through activation of IL-6/STAT3 signaling in human cholangiocarcinoma. Hepatology 59: 935-946, 2014

34. Sun W, Liu DB, Li WW, et al: Interleukin-6 promotes the migration and invasion of nasopharyngeal carcinoma cell lines and upregulates the expression of MMP-2 and MMP-9. Int J Oncol 44: 1551-1560, 2014. 